\title{
Hipertrofia Maciça das Mamas na Gravidez: Relato de Caso
}

\author{
Massive Hypertrophy of the Breasts in Pregnancy: A Case Report \\ Amadeu Ramos da Silva Filho ${ }^{1}$, Jayme Moyses Burlá ${ }^{1}$, Nilson Ramirez de Jesus ${ }^{1}$, \\ Nadia Dantas Gomes², Andréia Brandão Gonzalez ${ }^{3}$
}

\begin{abstract}
RESUMO
A hipertrofia maciça das mamas na gestação é uma situação rara, com poucos casos descritos na literatura. Apesar de a etiologia ser desconhecida, parece tratar-se de resposta exagerada dos receptores da mama aos hormônios gravidicos. Embora possa ocorrer em qualquer gravidez apresenta alta taxa de recorrência nas gestações subseqüentes. O rápido e descomunal aumento mamário determina, além da dor, o comprometimento do esqueleto e musculatura das espáduas. O excessivo crescimento pode provocar necrose da pele com formação de úlceras, favorecendo grave infecção das glândulas. Os autores relatam um caso ocorrido em secundigesta, expondo a conduta durante a gravidez e a inibição da lactação com uso da bromocriptina imediatamente após o parto, com enfaixamento das mamas elevadas. Realçam também a importância da mamoplastia redutora poucos meses após o parto.
\end{abstract}

PALAVRAS-CHAVE: Mama: hipertrofia. Mama: doença benigna. Complicações da gravidez.

\section{Introdução}

O exuberante e rápido crescimento das mamas, uni ou bilateralmente, em adolescentes e gestantes é condição poucas vezes observada.

A hipertrofia maciça das mamas ocorre em $1 / 100.000$ gestações $^{1-3}$, embora alguns autores a tenham observado em proporção mais baixa, como $1 / 28.000$ gestações $^{4,5}$. A etiologia precisa ser melhor conhecida, embora pareça ser resposta exagerada dos receptores mamários aos hormônios da gravidez, os quais se encontram com niveis séricos normais ${ }^{2,3,6}$. Entretanto, o uso de determinadas drogas durante o período gestacional pode, em rarissimas ocasiões, causar também exagerado crescimento do tecido mamário ${ }^{3,7}$. O exuberante crescimento bilateral das mamas

\footnotetext{
${ }^{1}$ Hospital Universitário Pedro Ernesto - Departamento de Saúde Materno e Infantil da Universidade do Estado do Rio de Janeiro

2 Disciplina de Anatomia Patológica - Departamento de Patologia e Laboratórios da Universidade do Estado do Rio de Janeiro

3 Hospital Universitário Pedro Ernesto - Instituto de Psicologia da Universidade do Estado do Rio de Janeiro Correspondência:

Amadeu Ramos da Silva Filho

Rua: Ministro Corrêa de Melo, 113 apto 802 - Leblon

22430-110 - Rio de Janeiro - RJ

Fone: (21) 2512-7274

Fone/Fax: (21) 2576-9896
}

pode ocorrer em doenças malignas como o linfoma não-Hodgkin, devendo por conseguinte ser considerado no diagnóstico diferencial desta hipertrofia ${ }^{8}$. Além das graves repercussões físicas representadas pela dor, ulcerações e infecção, que o crescimento mamário ocasiona, existe deteriorização da imagem corporal da paciente afetando de maneira pronunciada seu relacionamento familiar e social.

\section{Relato do Caso}

VPS, branca, 23 anos, gesta II para I, matriculou-se no ambulatório de assistência pré-natal do Hospital Universitário Pedro Ernesto da Faculdade de Ciências Médicas da Universidade do Estado do Rio de Janeiro em 19 de outubro de 2001, na $28^{a}$ semana de gravidez. Havia permanecido internada em nossa maternidade de 14 a 27 de setembro por apresentar, em mamas muito volumosas, ulcerações e sinais sugestivos de processo inflamatório.

Referia que a partir do primeiro mês gestacional suas mamas apresentavam-se avermelhadas, iniciando crescimento rápido e significativo, atingindo o tamanho atual no final do primeiro trimestre. Relatava dores tipo fisgadas em ambas as glân- 
dulas, além de dor na região das espáduas. Informava que, em gravidez anterior, de outro parceiro, havia apresentado alterações mamárias gravídicas normais, tendo amamentado por seis meses.

Ao exame físico, a gestante apresentava mamas hipertrofiadas bilateralmente, afetando sua postura fisica (Figura 1). Encontravam-se hiperemiadas, com áreas de celulite e linfedema (Figura 2). Ulcerações largas e rasas, por provável necrose da pele, eram observadas nos quadrantes externos da mama esquerda (Figura 3).

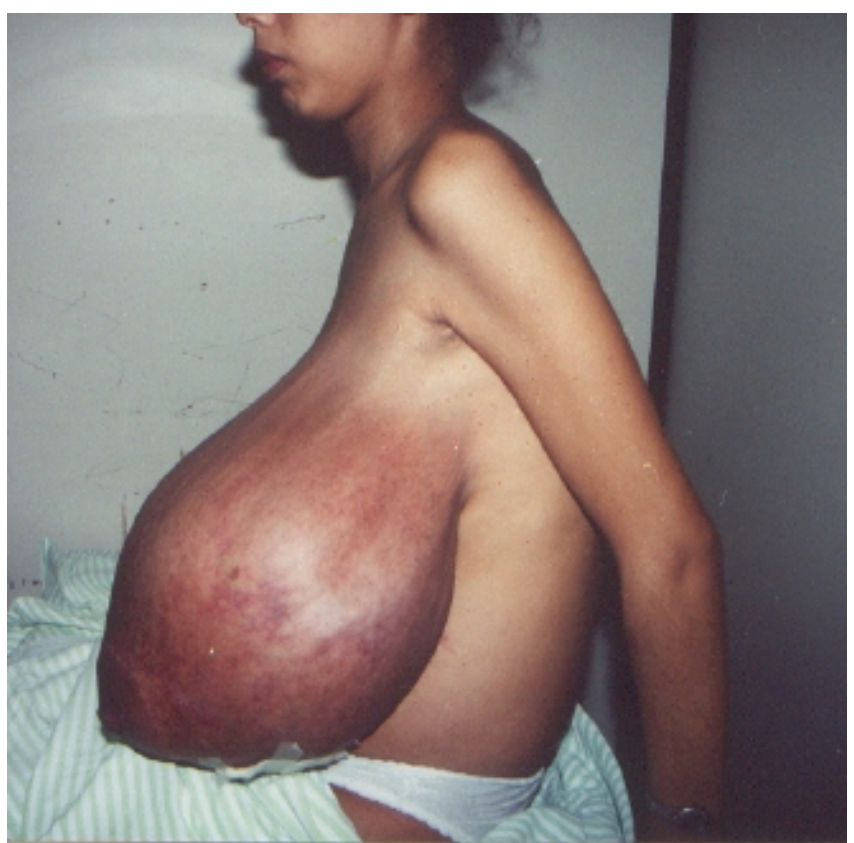

Figura 1 - Em visão lateral nota-se a ação das volumosas mamas sobre a estrutura músculo-esquelética das espáduas. Gravidez na $28^{\mathrm{a}}$ semana.

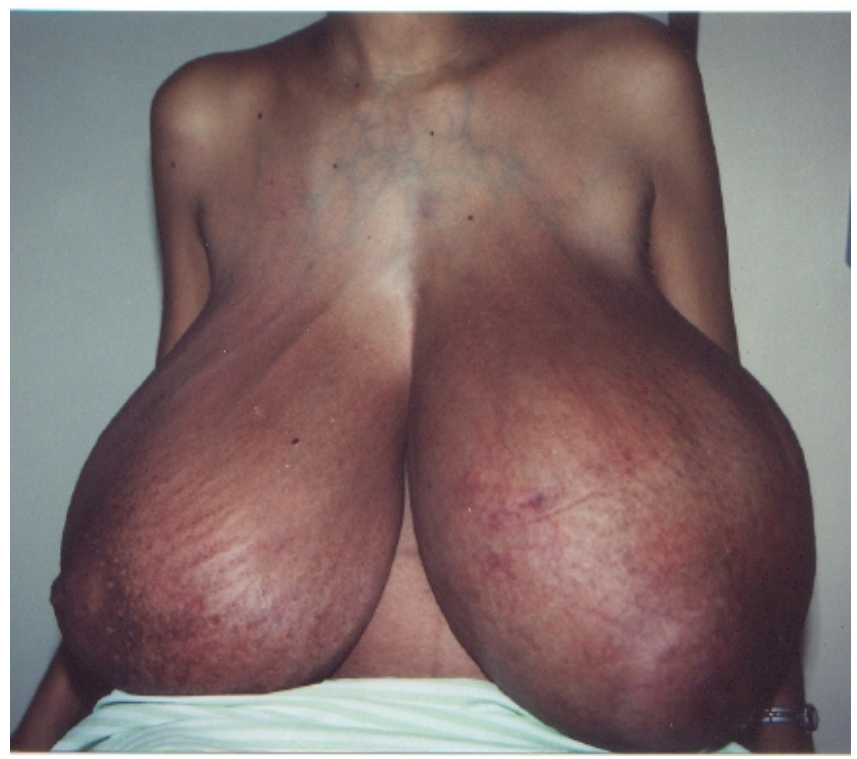

Figura 2 - Mamas hiperemiadas com intensa vascularização, apresentando áreas de celulite e linfedema.

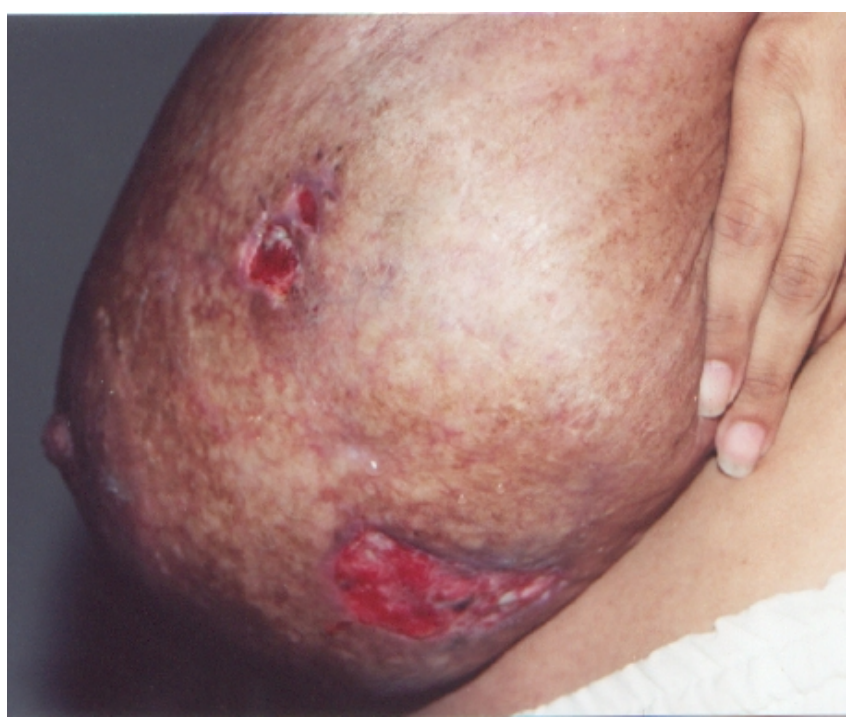

Figura 3 - Mama esquerda apresentando nos quadrantes externos ulcerações rasas de fundo limpo por necrose tegumentar.

A palpação era dolorosa e revelava parênquima macio e não se observava formações nodulares. O exame ultra-sográfico não evidenciava imagem nodular cística ou sólida em seu parênquima. As dosagens séricas da $\beta$ gonadotrofina e da prolactina apresentaram niveis de $37.100 \mathrm{mUI} /$ $\mathrm{mL}$ e $281 \mathrm{ng} / \mathrm{mL}$, respectivamente.

Foi realizada biópsia incisional em região próxima às ulcerações. O laudo histopatológico revelava hipertrofia e hiperplasia dos lóbulos, que se constituíam de ácinos de aspecto secretor. Chama a atenção, no estroma, a proeminência da vascularização capilar com hiperplasia de pericitos, bem como a hipertrofia estromal associada (Figuras 4 e 5).

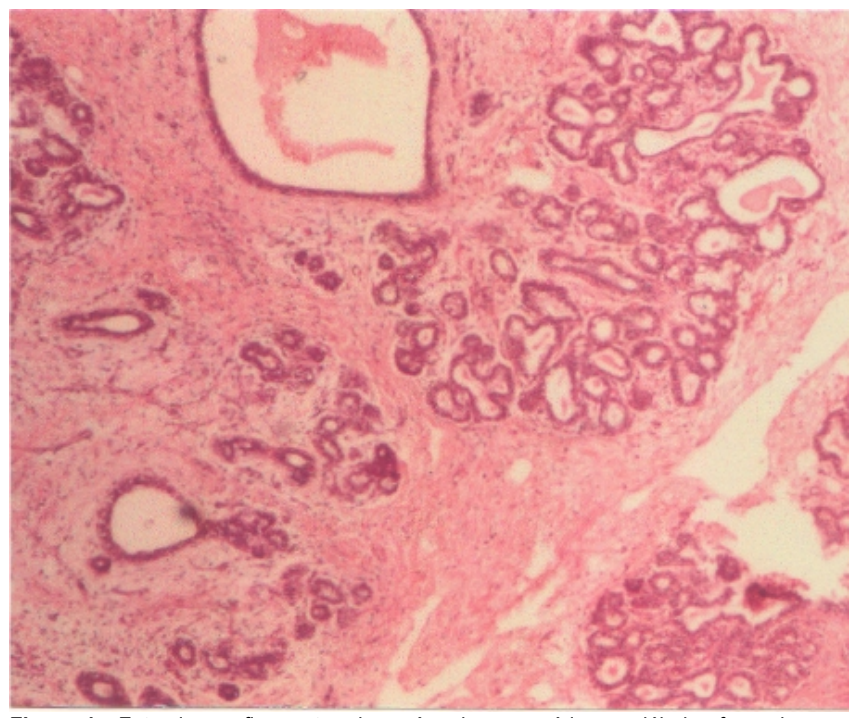

Figura 4 - Fotomicrografia mostrando parênquima mamário com lóbulos formados por ácinos parcialmente secretores. À esquerda observa-se estroma com vascularização proeminente (HE, X100). 


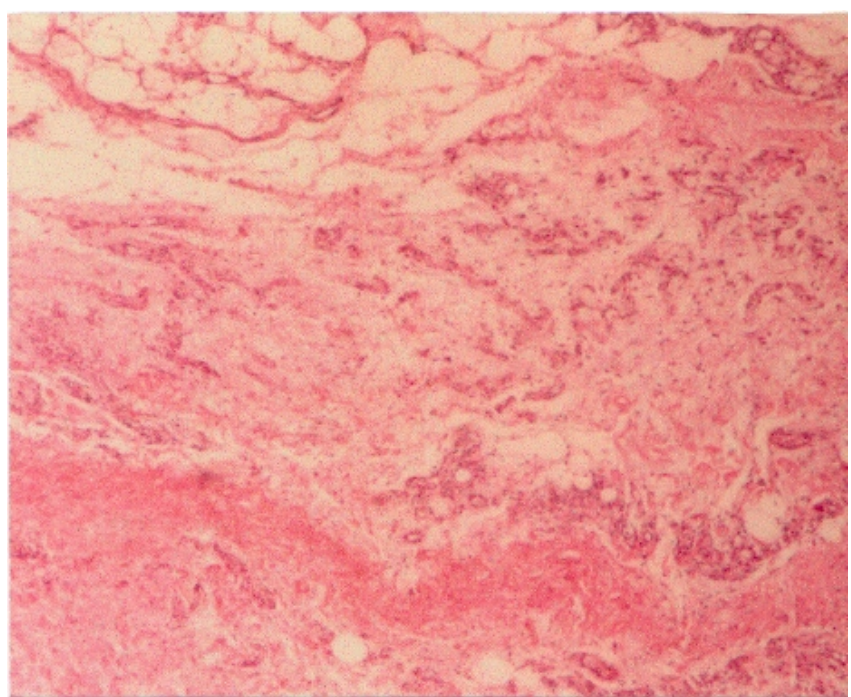

Figura 5 - Fotomicrografia demonstrando abaixo à direita estroma colagenizado. Na área central, numerosos capilares e edema (HE, X100).

A gestante foi orientada a manter as mamas elevadas, curativos diários com aplicação de colágeno nas ulcerações e uso de analgésicos por via oral quando necessário.

Encaminhada à consulta com a psicóloga do pré-natal. Nas cinco consultas subseqüentes as mamas apresentavam volumes estabilizados e melhora das ulcerações.

No dia 24 de dezembro de 2001 , na $37^{\mathrm{a}}$ semana de idade gestacional, a paciente foi admitida na maternidade em trabalho de parto. Após 3 horas deu à luz em parto espontâneo vaginal a feto vivo do sexo masculino com boa vitalidade, pesando 3.110 gramas e 40 semanas de idade gestacional avaliada pelo teste de Capurro. Iniciou-se imediatamente o uso de bromocriptina $7,5 \mathrm{mg} / \mathrm{dia}$, com a finalidade de inibir-se a lactogênese, além do enfaixamento e elevação das mamas. Alta hospitalar com 48 horas de pós-parto.

Fez uso da bromocriptina por cinco dias, ocorrendo alívio dos sintomas dolorosos e diminuição do volume mamário. Com 15 dias de pós-parto apresentou galactorréia espontânea e recrudescimento volumétrico das glândulas. Por orientação médica voltou a usar bromocriptina $7,5 \mathrm{mg} /$ dia durante uma semana, cessando a galactorréia. $\mathrm{Na}$ primeira semana da alta hospitalar as lesões ulcerativas começaram a regredir e, com um mês de puerpério, as ulcerações não mais existiam.

Em 16 de fevereiro de 2002, com cinqüenta e dois dias de pós-parto, veio à consulta pós-natal. Apresentava mamas hipertrofiadas, porém com volume nitidamente menor que o observado durante a gravidez. Não havia lesões ulcerativas e a coloração tegumentar era normal. À palpação o parênquima apresentava-se macio, indolor e sem evidências de nodulações e/ou coleções.
Foi colocado DIU T Cu 380 - A e a paciente encaminhada ao ambulatório da Clínica de Cirurgia Plástica para futura mamoplastia redutora.

\section{Discussão}

A hipertrofia maciça das mamas ou gigantomastia gestacional apresenta inúmeras incógnitas de dificeis respostas, embora algumas já estejam bem estabelecidas e aceitas pelos especialistas. É muito menos freqüente do que as hiperplasias observadas na adolescência, as quais podem ocorrer em ambos os $\operatorname{sexos}^{3,7}$. A excessiva resposta dos receptores mamários aos hormônios produzidos inicialmente pelo corpo amarelo e posteriormente pela placenta parece ser o elemento desencadeador do processo hiperplástico. Tanto os estrógenos como a gonadotrofina coriônica parecem estar envolvidos, embora seus valores séricos, assim como o da prolactina, estejam em níveis normais para a idade gestacional ${ }^{6}$. Em nosso caso os valores da gonadotrofina estavam compativeis com o terceiro trimestre, porém os niveis da prolactina apresentavam-se um pouco acima do esperado.

A hipertrofia das mamas tem sido observada em mulheres não grávidas quando tratadas com isoniazida, digital ${ }^{7}$ e terapia com penicilamina para artrite reumatóide; estas drogas parecem contribuir na falha da inativação hepática do estrogênio e maior estímulo ao crescimento das glândulas mamárias.

O exagerado aumento volumétrico ocorre tanto nas primo ${ }^{2,3,9,10}$ quanto nas multigrávidas $^{4,11,12}$, podendo iniciar-se desde a percepção da falha menstrual mas mais freqüentemente observado no final do primeiro trimestre, período que coincide com o fenômeno do pico de produção gonadotrófica. A participação paterna, à semelhança do que ocorre na mola hidatiforme completa, é ressaltada como possivel contribuição na gênese desta incomum doença ${ }^{3}$. Alguns autores referem surgimento da hiperplasia maciça das mamas em mulheres com antecedentes de gestações normais e que, após se divorciarem, engravidaram com outro parceiro ${ }^{3,13}$. O caso por nós apresentado ocorreu em segunda gravidez, com parceiro sexual diferente.

O sexo fetal parece não ter relevância etiológica, parecendo tratar-se de pura coincidência quando o mesmo sexo é encontrado em associação com a gigantomastia ${ }^{3}$. Embora possa não ocorrer na primeira, segunda ou terceira gravidez, uma vez tendo ocorrido a hipertrofia maciça das mamas complica todas as gestações subseqüentes se a paciente não for submetida à mamoplastia re- 
dutora ou mastectomia ${ }^{4,12}$. Esta recorrência pode ser observada mesmo em gestações que evoluem para o abortamento espontâneo ${ }^{14}$.

O crescimento rápido e exagerado das mamas pode provocar lesões ulceradas, infecção e por vezes necrose da própria glândula, o que justificaria, em décadas passadas, a interrupção da gravidez ainda nas primeiras semanas ${ }^{10}$ ou mastectomia ${ }^{13,15}$. Atualmente, com o emprego dos estimuladores dos receptores dopaminérgicos, podemos adotar condutas menos agressivas. O crescimento intra-uterino restrito pode ser observado em alguns $\operatorname{casos}^{3,4,15}$, embora não tenham sido encontradas alterações placentárias nos casos relatados. O aumento excessivo das mamas, desviando, em parte, nutrientes necessários ao feto, poderia justificar esta ocorrência ${ }^{3}$.

O aspecto histológico do tecido mamário obtido por biópsia, mastectomia ou mamoplastia redutora é de hiperplasia glandular e importante aumento do tecido conectivo com ausência de tecido adiposo. Por vezes observam-se ductos e vasos linfáticos dilatados, fibroadenomatose e formações císticas ${ }^{2,3,6,7,15,16}$. Infiltrado linfomatoso e linfedema foram observados na hipertrofia mamária bilateral de grávida portadora de linfoma nãoHodgkin ${ }^{8}$.

O tratamento proposto para a hiperplasia maciça das mamas durante a gestação está orientado para melhorar as condições atuais da gestante, sobretudo a dor que a mesma provoca. No caso por nós apresentado foi confeccionado um suporte tipo porta-seios que mantinha as mamas elevadas, prescrito uso de paracetamol quando necessário e o curativo diário das ulcerações, que permaneceram oclusas. Propõe-se o uso de bromocriptina e/ou progesterona, capazes de diminuírem a dor e o intumescimento glandular ${ }^{3}$.

A bromocriptina em doses de 5 a $7,5 \mathrm{mg} /$ dia foi utilizada por numerosos autores ${ }^{3,4,9,14} \mathrm{com}$ bons resultados mesmo quando iniciada após o sétimo mês gestacional. Entretanto, a necrose com subseqüente ulceração da pele mamária parece não ser evitada ou minimizada com o uso da droga ${ }^{10}$, além das queixas de náuseas e vômitos relatadas por algumas grávidas. A progesterona atualmente não tem sido usada pelos pobres resultados quando comparada à bromocriptina. No caso apresentado a gestante iniciou o pré-natal em fase avançada, com dor que melhorou com as recomendações já relatadas e sem progressão do aumento mamário. As visitas médicas devem ser realizadas a intervalos curtos com especial observação dos sinais sugestivos de infecção; nestes casos a terapêutica antibiótica deve ser prontamente instituída.

A gestação deve ser levada a termo aguardando-se o início espontâneo do trabalho de parto e, quando possivel, solução vaginal. Ocasionalmente observa-se crescimento fetal restrito ${ }^{3}$ justificando, nestes casos, o rastreamento do seu bem-estar e, se necessário, interrupção da gravidez. O suporte psicológico deve ser plenamente oferecido. Estas pacientes tornam-se motivo de curiosidade e chacota e freqüentemente encontram-se profundamente deprimidas.

A inibição da lactogênese com bromocriptina $7,5 \mathrm{mg} /$ dia deve ser iniciada logo após o parto, porque o ingurgitamento da mama pode precipitar infecção e necrose ${ }^{12}$. A mamoplastia redutora deve ser indicada, embora a involução espontânea tenha sido relatada ${ }^{3}$.

Não havendo comprometimento como necrose e/ou infecção, a redução volumétrica pela mamoplastia deve ser postergada, para após o quarto mês pós-parto.

$\mathrm{Na}$ vivência da mulher, a mama tem acentuada importância em sua imagem corporal e identidade feminina, sua atração e sexualidade e para o seu papel como mãe nutriz. Assim sendo, pode-se dizer que a deformação deste órgão representa um abalo no sentimento de valor próprio, elemento essencial para a saúde física e mental de uma mulher.

\section{ABSTRACT}

Massive hypertrophy of the breast in pregnancy is a rare condition, with few cases reported. In spite of the unknown etiology, it seems to be an exaggerated response of the breast receptors to the pregnancy hormones. Although it can happen in any pregnancy, it presents great capacity to recur in all subsequent pregnancies. The rapid and colossal breast enlargement determines pain and the involvement of the shoulder skeleton and muscles. The excessive enlargement may promote necrosis and ulceration of the skin, leading to breast infection. The authors report one case at the second pregnancy, explaining management during the pregnancy, lactation inhibition with bromocriptine immediately after the delivery and the banding of the elevated breast. They also emphasize the importance of reduction mammoplasty a few months after delivery.

KEY WORDS: Gigantomastia in pregnancy. Benign disease of the breast. Complications of pregnancy.

\section{Referências}

1. Menschik T, Lindner C, Kunert P, Janicke F. Pregnancyinduced gigantomastia: a disease picture of uncertain origin. Zentralbl Gynakol 1999; 121:14-7. 
2. Zienert A. Macromastia in pregnancy: normal or a complication? Zentralbl Gynakol 1990; 112:1303-7.

3. Beischer NA, Hueston JH, Pepperell RJ. Massive hypertrophy of the breasts in pregnancy: report of 3 cases and review of the literature, "never think you have seen everything". Obstet Gynecol Surv 1989; 44:234-43.

4. Kullander S. Effect of 2 Br-alpha-ergocryptin (CB 154) on serum prolactin and the clinical picture in a case of progressive gigantomastia in pregnancy. Ann Chir Gynaecol 1976; 65:227-33.

5. Wølner-Hanssen P, Palmer B, Sjüberg NO, Astedt B. Gigantomastia. Acta Obstet Gynecol Scand 1981; 60:525-7.

6. Van der Meulen AJ. An unusual case of massive hypertrophy of the breasts. S Afr Med J 1974; 48:1465-6.

7. Reyna Hinojosa R, Martinez Medellin J, Ceballos Quiroz R, Torres Huerta FR. Hipertrofia masiva de la glándula mamaria. Presentación de seis casos. Ginecol Obstet Mex 1997; 65:277-81.

8. Windom KW, McDuffie RS Jr. Non-Hodgkin's lymphoma presenting with gigantomastia in pregnancy. Obstet Gynecol 1999; 93:852-4.

9. Hedberg K, Karlsson K, Lindstedt G. Gigantomastia during pregnancy: effect of a dopamine agonist. Am J Obstet Gynecol 1979; 133:928-31.
10. Miller CJ, Becker DW. Management of first trimester breast enlargement with necrosis. Plast Reconstr Surg 1979; 63:383-6.

11.Nolan JJ. Gigantomastia: report of a case. Obstet Gynecol 1962; 19:526-9.

12.Lewison EF, Jones GS, Trimble FH, Lima LC. Gigantomastia complicating pregnancy. Surg Gynecol Obstet 1960; 110:215-23.

13. Greeley PW, Robertson LE, Curtin JW. Mastoplasty for massive bilateral benign breast hypertrophy associated with pregnancy: case report. Ann Surg 1965; 162:1081-3.

14.Leis SN, Palmer B, Östberg G. Gravid macromastia: case report. Scand J Plast Reconstr Surg 1974; 8:247-9.

15.Williams PC. Massive hypertrophy of the breasts and axillary breasts in successive pregnancies. Am J Obstet Gynecol 1957; 74:1326-9.

16.Wolf Y, Pauzner D, Groutz A, Walman I, David MP. Gigantomastia complicating pregnancy. Case report and review of the literature. Acta Obstet Gynecol Scand 1995; 74:159-63.

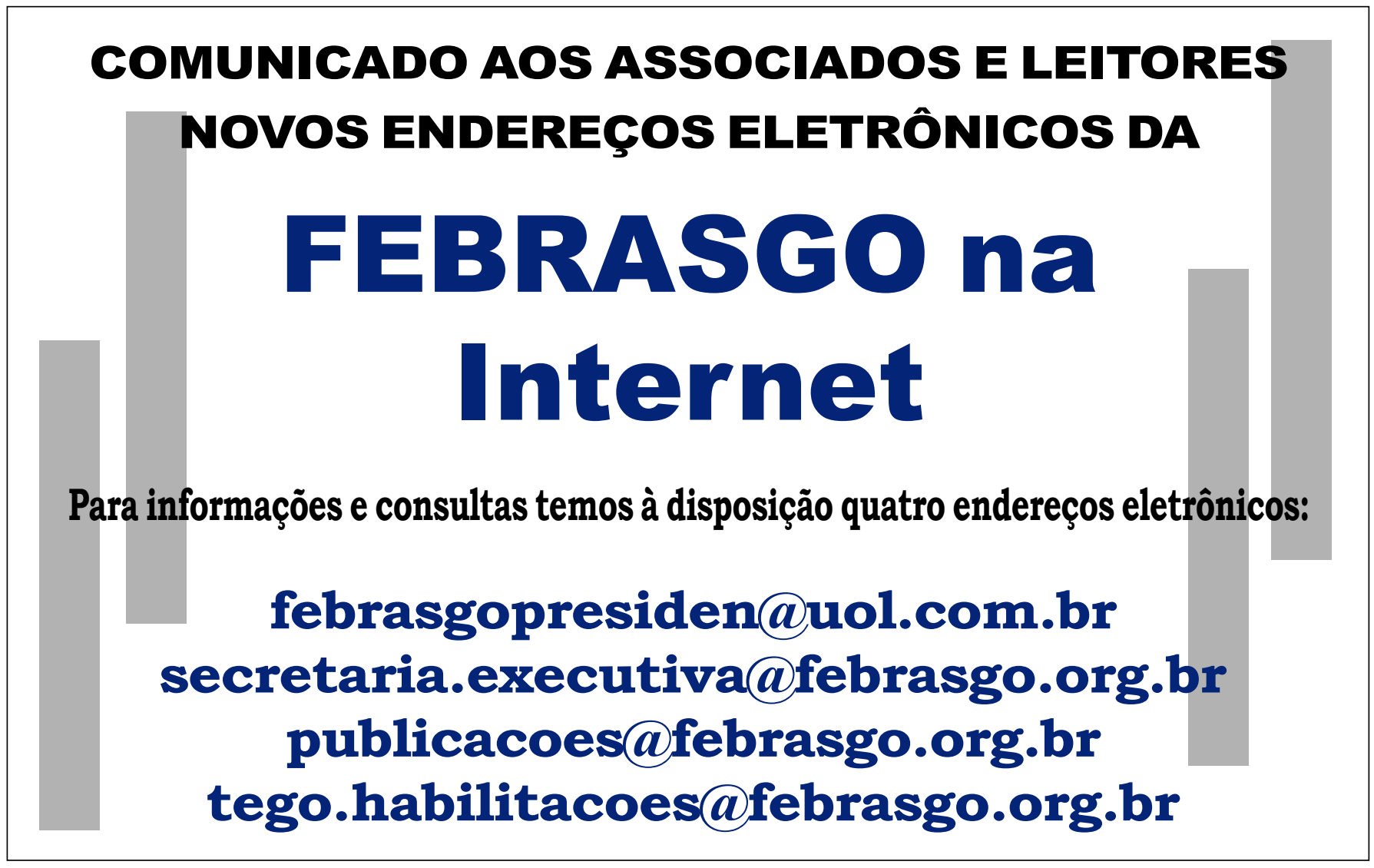

